\title{
Use of Engineering Mathematics for Ship Design
}

\author{
Cristiano Fragassa ${ }^{1, * \mathbb{C}}$, Elizaldo Domingues dos Santos ${ }^{2}$ and Felipe Vannucchi de Camargo ${ }^{1,3}$ (I) \\ 1 Department of Industrial Engineering, Alma Mater Studiorum Università di Bologna, \\ Viale del Risorgimento 2, 40136 Bologna, Italy; felipe.vannucchi@unibo.it \\ 2 School of Engineering, Universidade Federal do Rio Grande (FURG), Italia Av., km 8, \\ 96211-090 Rio Grande, Brazil; elizaldosantos@furg.br \\ 3 Post-Graduation Program in Mining, Metallurgical and Materials Engineering, \\ Federal University of Rio Grande do Sul, Rua Osvaldo Aranha 99, 90035-190 Porto Alegre, Brazil \\ * Correspondence: cristiano.fragassa@unibo.it; Tel.: +39-347-697-4046
}

Received: 11 October 2019; Accepted: 17 October 2019; Published: 17 October 2019

With over that $70 \%$ of the Earth submerged by seas, continents separated by oceans, two thousand major islands scattered throughout the World, hundreds of thousands of kilometers of navigable rivers, maritime or fluvial transport surely represents one of the most important ways of moving people, goods, and wealth around the globe. This kind of transport has been widely used along the human history and development, allowing achievements not reachable in any other way in commercial, economic, technological, and even social aspects. As a consequence, the study of topics related to the ships design has always been a relevant aspect in every civilization and time. From the moment when the man has decided to face the sea on a boat up to the present day, a myriad of designers has posed the same fundamental question: 'are there knowledge or tools that can support the design of my boat in the way to make it as fast and safe as possible?'. This notable question was for who prepared the boat for the pharaoh about 3000 years before the Jesus Christ, as for who is designing the new catamaran for the next American's cup just now. However, fortunately, these centuries have allowed us to develop a profound knowledge of marine engineering, including a large range of methods and techniques useful for every boat designer.

Engineering mathematics, in particular, is a study field where mathematical methods and solving techniques are combined, regardless of the (analytical, numerical, or experimental) approach to offer a response to physical dilemma and to solve practical engineering problems.

In the present edition, this knowledge is employed to obtain several important recommendations about diversified fields of ship design, from the structural analysis in hulls up to methods that take into account the environmental sustainability in maritime transports.

Concerning the structural analysis and external forces over the vessels, this edition brings numerical studies about the influence of external forces (as the wind, inertial, and wave forces) over the trajectory of the ship and the effect of geometric configuration of stiffened plates under supported load in structures commonly found in hulls. It is also developed analytical methods based on single-stepped planning hulls for prediction of hydrodynamic forces over the structure of vessels. The influence of fluid structure interaction phenomena due to air cavity formation commonly found in naval applications and the employment of numerical methods for calculation of the roll motion in vessels are also investigated. Moreover, a survey on experimental and numerical approaches to model underwater explosions is explored, being a relevant study for adequate structural dimensioning of ships, especially for military vessels.

Investigations about propulsion systems are also presented. In this realm, the numerical study of propulsion devices based on Coanda effect are proposed and the evaluation of its main operational principle for thrust and maneuverability in marine applications is performed. 
Additionally, the estimated fuel consumption in dual-fuel two-stroke marine engines are analyzed, improving knowledge about selection of most efficient engines for naval applications.

To summarize, it is also performed an integrated analysis of the Environmental Management Systems and Balanced Scorecard for operation of marine transport taking into account environmental protection. We trust that this special edition will be helpful to improve comprehension of ship design and how the application of engineering mathematics can support the pursuit of knowledge in this research field.

Conflicts of Interest: The authors declare no conflict of interest.

(C) 2019 by the authors. Licensee MDPI, Basel, Switzerland. This article is an open access article distributed under the terms and conditions of the Creative Commons Attribution (CC BY) license (http://creativecommons.org/licenses/by/4.0/). 